Hamburger Rechtsstudien

herausgegeben von Mitgliedern der Rechtswissenschaftlichen Fakultät der Universität Hamburg

\title{
Heft 46
}





\section{Die Zurechnung}

Ein Zentralproblem des Strafrechts

von

Dr. jur. WERNER HARDWIG

Privatdozent

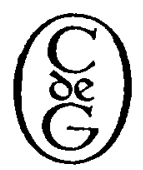

Hamburg

Cram, de Gruyter \& Co.

1957 
Als Habilitationsschrift auf Empfehlung der Rechtswissenschaftlichen Fakultät der Universität Hamburg gedrudkt mit Unterstützung der Deutschen Forschungsgemeinschaft

(C) Copyright 1957 by Cram, de Gruyter \& Co.

Alle Rechte einschließlich der Rechte auf Herstellung von Photokopien und Mikrofilmen vorbehalten.

Satz und Drudk: \& Saladruck, Berlin N 65. 